\title{
Short-term effects of airborne pollens on asthma attacks as seen by general practitioners in the Greater Paris area, 2003-2007
}

\section{Bich Tram Huynh ${ }^{a}$, Séverine Tual ${ }^{a}$, Clément Turbelin ${ }^{b}$, Camille Pelat ${ }^{b}$, Lorenzo Cecchic, Gennaro D'Amato ${ }^{d}$, Thierry Blanchon ${ }^{b}$, *Isabella Annesi-Maesano ${ }^{a}$}

\author{
a INSERM and UPMC Paris VI EPAR, Medical School Saint-Antoine, Paris, France \\ ${ }^{\mathrm{b}}$ INSERM and UPMC Paris VI, Paris, France \\ ' University of Florence, Florence, Italy \\ ${ }^{d}$ Ospedale Cardarelli, Naples, Italy
}

Received 28th October 2009; resubmitted 14th January 2010; revised 22nd February 2010; accepted 6th April 2010; online 8th June 2010

\begin{abstract}
Aims: To investigate for the first time the short-term effects of airborne pollen counts on general practitioner (GP) consultations for asthma attacks in the Greater Paris area between 2003-2007

Methods: Counts were available for common pollens (Betula, Cupressa, Fraxinus and Poaceae). Weekly data on GP visits for asthma attacks were obtained from the French GP Sentinel Network. A quasi-Poisson regression with generalised additive models was implemented. Short-term effects of pollen counts were assessed using single and multi-pollen models after adjustment for air pollution and influenza.

Results: A mean weekly incidence rate of 25.4 cases of asthma attacks per 100,000 inhabitants was estimated during the study period. The strongest significant association between asthma attacks and pollen counts was registered for grass (Poaceae) in the same week of asthma attacks, with a slight reduction of the effect observed in the multi-pollen model. Adjusted relative risk for Poaceae was 1.54 (95\% $\mathrm{Cl}$ : 1.33-1.79) with an inter-quartile range increase of 17.6 grains $/ \mathrm{m}^{3}$ during the pollen season.

Conclusions: For the first time, a significant short-term association was observed between Poaceae pollen counts and consultations for asthma attacks as seen by GPs. These findings need to be confirmed by more consistent time-series and investigations on a daily basis. (C) 2010 Primary Care Respiratory Society UK. All rights reserved. I Annesi-Maesano et al. Prim Care Resp J 2010; 19(3): 254-259 doi:10.4104/pcrj.2010.00027
\end{abstract}

Keywords asthma, exacerbations, pollen, consultations, GPs, epidemiology

\section{Introduction}

The prevalence of respiratory and allergic disorders has increased world-wide particularly in the case of asthma. ${ }^{1}$ The aetiology of asthma is multifactorial and includes interactions between genetic predisposition and environmental factors. Changes in environmental factors, such as climate, air pollution and airborne pollen may partly explain this increase. ${ }^{2}$ Pollen is a well known trigger of allergies and asthma aggravation, and actually has a changing profile. ${ }^{3}$ New sources of pollen have emerged following the use of ornamental plants in public and private places. Moreover, global climate change has been linked to an earlier onset and an extended duration of the pollen season, to an increase in pollen production, and a stronger allergenicity for some pollen types. ${ }^{4}$ Thunderstorm asthma epidemics may be triggered by grass pollen rupture in the atmosphere and the entrapment of respirable-sized particles in the outflows of air masses at ground level. ${ }^{3,4}$ Increasing pollution is responsible for an increase in pollen-induced respiratory allergy, including asthma, because of airway inflammatory reaction and the

\footnotetext{
* Corresponding author: Dr Isabella Annesi-Maesano, INSERM and UPMC Paris VI EPAR, Medical School Saint-Antoine, 27, rue Chaligny, Paris, 75012, France. Tel: +33144738449 Fax: +33144738454 E-mail: annesi-maesano@u707.jussieu.fr
} 
passage of pollen grains into the lower respiratory tract. ${ }^{3}$

Several epidemiological studies have controlled for pollen counts when investigating air pollutant effects on allergic and respiratory disease morbidity, including asthma..$^{5-7}$ Most studies have focused on the short-term impact of airborne allergenic pollens on asthma by considering hospital daily admissions or emergency room (ER) visits for asthma. ${ }^{8.12}$ However, most wellcontrolled asthmatic patients who develop an exacerbation do not attend the ER but consult their general practitioner (GP). To our knowledge, no study of the effects of pollens on asthma attacks has been undertaken at the primary care level.

The present study explored the short-term effects of airborne pollens on asthma attacks requiring a GP consultation - after adjustment for air pollution, meteorological conditions and influenza - in Paris and its surrounding area, using an appropriate model, over the period 2003-2007. If the link between airborne pollen counts and asthma attacks seen by a GP were to be confirmed, the public health impact would be considerable.

\section{Methods}

\section{Study area}

The study area was chosen in order to ensure a representative sample of asthmatic patients' exposure to pollens and other air pollutants, meteorological data, and asthma exacerbations. The Greater Paris area (the city of Paris and its surrounding areas) satisfied these requirements as it provided high-quality real-time temporal surveillance of asthma attacks during the study period as well as monitoring stations which monitor pollens, air pollutants and meteorological data.

\section{GP consultations for asthma attacks}

Data on weekly counts of asthma attacks requiring a GP consultation were obtained between January 2003 and December 2007 from the 257 GPs in the French Sentinel Network (FSN) working in the Greater Paris area; 1,270 GPs have been recruited to the FSN nationally (i.e. $2 \%$ of the total number of French GPs). ${ }^{13}$ The FSN is the national system of clinical surveillance collecting real-time data on major diseases to be used in health analysis, forecasting and redistribution. ${ }^{14,15}$ GPs participate on a volunteer basis in the weekly surveillance of 14 health indicators, including asthma attacks, by reporting the number of cases seen in their practice and their characteristics (age, gender, smoking status, asthma status, hospitalisation and treatment).

In this study, in agreement with previous literature used by physicians in France (http://www.caducee.net/DossierSpecialises/ Pneumologie/asthme.asp), an asthma attack was defined for individuals more than 3 years old as an episode of acute respiratory dyspnoea with wheeze and/or coughing, excluding exacerbation of chronic obstructive pulmonary disease (COPD) or left cardiac failure, and for children under 3 years of age as a wheezing episode, including bronchiolitis (only after the third episode). 189 asthmatic patients were seen by the FSN GPs over the four-year study period, 177 of which were fully described in terms of socio-demographic and clinical variables. All studies using FSN data are approved by the French National Commission for Data protection and the Liberties (n: 471393).

\section{Pollen, air pollution and meteorological data}

Data on pollens were collected from February to September by the French National Network of Aerobiologic monitoring (RNSA) ${ }^{17}$ through the unique HIRST monitoring station located $5 \mathrm{~km}$ southwest of Paris (roof of Pasteur Institute) which covers a radius of $30 \mathrm{~km}$ corresponding to the entire study area. The four pollens studied are those with the highest allergenicity and spread in Paris and its surrounding area: Betula (birch); Cupressa (cypress); Fraxinus (ash); and Poaceae (grass). Since the data on asthma attacks were measured on a weekly basis, the daily counts of pollens grains per $\mathrm{m}^{3}$ were averaged over each week.

Air pollution data were provided by the French Environment and Energy Management Agency (ADEME) from monitoring stations located in the study area, reflecting background pollution. ${ }^{18}$ Monitored air pollutants were: nitrogen dioxide $\left(\mathrm{NO}_{2}\right)$ - data obtained from 19 monitoring stations; particulate matter of less than $10 \mu \mathrm{m}$ diameter $\left(\mathrm{PM}_{10}\right)$ and sulphur dioxide $\left(\mathrm{SO}_{2}\right)$ - data from seven stations; and ozone $\left(\mathrm{O}_{3}\right)$ - data from 13 stations. Daily concentrations of these pollutants were averaged on a weekly basis and expressed as $\mu \mathrm{g}$ per $\mathrm{m}^{3}$.

Meteorological data were obtained from the French Meteorological Office (Météo-France); ${ }^{19}$ data from one station out of four were used, located $5 \mathrm{~km}$ south of Paris (Montsouris Park) and $3 \mathrm{~km}$ away from the pollen trap. Mean temperature (in degrees (elsius) and mean relative humidity (in \%) were registered by the Paris meteorological observatory. These daily meteorological data were averaged weekly.

\section{Statistical analysis}

The mean weekly incidence rate of asthma attacks per 100,000 inhabitants in the Greater Paris area was estimated using methodology previously validated by the FSN. ${ }^{16}$ Successively, a generalised additive model (GAM) was fitted to assess possible non-linear short-term associations between asthma attacks and pollens on a weekly basis after controlling for potential confounders, using a Poisson distribution with a log-link function. ${ }^{20,21}$ Over-dispersion was controlled using the quasilikelihood method. Associations between pollen and asthma attacks counts were adjusted for asthma trend and seasonality, air pollution data and meteorological variables. The potential confounding effects of public holidays and influenza were also controlled for in the model as, respectively, a dummy variable and the weekly incidence rate (per 100,000 inhabitants) obtained from the FSN. ${ }^{14}$ To eliminate autocorrelation resulting from temporal variations of asthma counts, pollen counts, meteorological data, air pollutants and influenza, we used a locally non-parametric regression (loess) as a temporal filter. ${ }^{22,23}$ Seasonality of asthma 
counts was taken into account by applying this function with a smoothing window of six months. ${ }^{20}$ The smoothing spans of loess function applied to other temporal variables were chosen on the basis of minimisation of (1) the Akaike information criterion, and (2) the sum of partial autocorrelation function (PACF) of the residuals, and (3) on the observation of PACF plots of the residuals.

Effects of pollen counts, pollutant concentrations and meteorological factors were investigated using the same lag. They were tested at lag 0 ( $\operatorname{lag} 0$ ) - i.e. during the week of the asthma attack - and three (lag 3) and six (lag 6) days earlier to evaluate the possible delayed effect of environmental data on asthma exacerbations. The best lag was chosen on the basis of the same criteria as the span for the loess functions. The short-term effects of pollen counts were firstly assessed using independent single pollen models, and secondly using a multi-pollen model. The effect of pollen counts on the weekly number of GP consultations for asthma attacks was expressed for linear relationships as the relative risk associated with an inter-quartile range (IQR) increase in pollen counts during the pollen season and its 95\% confidence interval. Due to the large number of pollens and lags tested, tests were considered to be statistically significant at the threshold of $1 \%$ (two-sided). All statistical analyses were performed using $\mathrm{R}$ version 2.6.2.

\section{Results}

A mean weekly incidence rate of 25.4 (range 0-307) cases of asthma attacks requiring GP consultation per 100,000 inhabitants was estimated for the Greater Paris area between 2003 and 2007. ${ }^{16}$ The average age (standard deviation) of patients with asthma attacks was 34.7 years $(23.2)$; $6 \%$ were under 3 years old, 18\% were between 3 and 15 years old, and $76 \%$ were aged over 15 years. Sixty-nine percent were women, $20 \%$ were smokers, and $73 \%$ were known to be asthmatic. Among the remainder, $42 \%$ were under 15 years old and $14 \%$ were over 60 years old. Six percent of the patients were hospitalised after their asthma attack.

Summary statistics of pollen counts, pollutant concentrations and meteorological variables are shown in Table 1. During the studied pollen seasons, the weekly means of Cupressa, Fraxinus and Poaceae counts varied from 13.2 to 16.9 grains $/ \mathrm{m}^{3}$ while Betula reached 35 grains $/ \mathrm{m}^{3}$ (Table 1). There was a coincidence in time between peaks in the Betula and Fraxinus pollen counts and asthma incidence in April 2004 and 2006 (data not shown). A light coincidence was seen also for Poaceae pollen peak in late June 2003.

All types of pollens were positively and significantly correlated with each other (Table 2), in particular Cupressa, Fraxinus and Poaceae $(r<=0.8)$. Pollen counts were positively correlated with ozone and negatively with humidity. Cupressa and Poaceae counts were significantly negatively correlated with $\mathrm{NO}_{2}$ and $\mathrm{SO}_{2}$ and positively with temperature.

The GAMs included a loess function with a smoothing window equal to 6 months for the time variable to control for trend and seasonality, dummy variable for public holidays and loess functions with a smoothing span of 0.2 for temperature, humidity, $\mathrm{NO}_{2}, \mathrm{O}_{3}, \mathrm{PM}_{10}, \mathrm{SO}_{2}$ and weekly incidence rate of influenza. The best adjustment in the single pollen models was made by loess functions with a smoothing span of 0.9 for Betula, 0.6 for Cupressa, 0.7 for Fraxinus and 0.7 for Betula. Non-parametric smoothing applied to Betula, Fraxinus and

Table 1. Descriptive analysis of pollens, air pollutants, meteorological variables, Paris and surrounding area, 2003-7.

\section{Percentiles}

\begin{tabular}{|c|c|c|c|c|c|c|c|c|c|}
\hline \multicolumn{10}{|l|}{ Pollens } \\
\hline Betula $\left(\text { grains } / \mathrm{m}^{3}\right)^{\star}$ & 153 & $35.0(83.6)$ & 0.1 & 0.3 & 1.3 & 16.6 & 96.0 & 230.9 & 503.9 \\
\hline Cupressa (grains $\left./ \mathrm{m}^{3}\right)^{\star}$ & 89 & $16.9(40.6)$ & 0.1 & 1.0 & 2.9 & 9.6 & 44.1 & 96.0 & 302.1 \\
\hline Fraxinus (grains $\left./ \mathrm{m}^{3}\right)^{*}$ & 93 & $13.2(31.6)$ & 0.1 & 0.3 & 1.0 & 7.4 & 39.4 & 77.8 & 206.6 \\
\hline Poaceae $\left(\text { grains } / \mathrm{m}^{3}\right)^{\star}$ & 164 & $14.1(23.3)$ & 0.1 & 0.7 & 3.0 & 18.3 & 45.5 & 72.3 & 121.9 \\
\hline $\mathrm{NO}_{2}\left(\mu \mathrm{g} / \mathrm{m}^{3}\right)$ & 261 & $39.6(11.2)$ & 15.4 & 31.1 & 39.5 & 47.3 & 52.2 & 55.3 & 86.9 \\
\hline $\mathrm{O}_{3}\left(\mu \mathrm{g} / \mathrm{m}^{3}\right)$ & 261 & $38.6(20.9)$ & 3.7 & 20.4 & 36.9 & 52.9 & 65.0 & 75.3 & 112.3 \\
\hline $\mathrm{PM}_{10}\left(\mu \mathrm{g} / \mathrm{m}^{3}\right)$ & 261 & $21.5(6.1)$ & 10.4 & 17.3 & 20.3 & 24.3 & 28.3 & 33.0 & 52.6 \\
\hline $\mathrm{SO}_{2}\left(\mu \mathrm{g} / \mathrm{m}^{3}\right)$ & 261 & $6.5(3.9)$ & 0.8 & 3.7 & 5.6 & 8.8 & 11.5 & 13.7 & 25.7 \\
\hline Meteorological variables & 261 & & & & & & & & \\
\hline
\end{tabular}




\begin{tabular}{|c|c|c|c|c|}
\hline & Betula & Cupressa & Fraxinus & Poaceae \\
\hline \multicolumn{5}{|l|}{ Pollens } \\
\hline Betula & 1.00 & & & \\
\hline Cupressa & $0.31 *$ & 1.00 & & \\
\hline Fraxinus & $0.18^{*}$ & $0.76^{*}$ & 1.00 & \\
\hline Poaceae & $0.52 *$ & $0.75^{*}$ & $0.77 *$ & 1.00 \\
\hline \multicolumn{5}{|l|}{ Pollutants } \\
\hline $\mathrm{NO}_{2}$ & -0.05 & $-0.21 *$ & 0.10 & $-0.64^{\star}$ \\
\hline $\mathrm{O}_{3}$ & 0.41 * & $0.57 *$ & 0.31 * & $0.85^{*}$ \\
\hline $\mathrm{SO}_{2}$ & 0.01 & $-0.18^{*}$ & 0.12 & $-0.58^{*}$ \\
\hline $\mathrm{PM}_{10}$ & 0.04 & 0.03 & 0.11 & 0.00 \\
\hline \multicolumn{5}{|l|}{$\begin{array}{l}\text { Meteorological } \\
\text { variables }\end{array}$} \\
\hline Mean temperature $\left({ }^{\circ} \mathrm{C}\right)$ & 0.04 & $0.25^{*}$ & -0.05 & $0.80 *$ \\
\hline Relative humidity (\%) & $-0.41 *$ & $-0.56^{\star}$ & $-0.34^{*}$ & $-0.70^{*}$ \\
\hline
\end{tabular}

Poaceae were not statistically significant in single pollen GAMs, at the threshold of $1 \% \quad(p=0.0394, p=0.4115, p=0.7745$ respectively). From our models, relationships between the various pollens and the number of asthma attacks requiring $G P$ consultation were found to be linear except in the case of Cupressa pollens for which the relationship was non-linear. According to single pollen models, a significant increase in asthma attack counts was significantly associated with an IQR rise in Poaceae ( $R R=1.70$ (95\% Cl=1.47-1:97)) and Betula counts ( $R R=1.07$ (1.04-1.11)) (see Table 3). The association between Fraxinus and asthma attack counts was of borderline statistical significance considering a threshold of $1 \%$.

In the multi-pollen model, the magnitude of the associations was slightly reduced for all types of pollens and became nonsignificant for Betula and Fraxinus (Table 3). The highest magnitude was observed for Poaceae with an adjusted relative risk of 1.54 (95\% Cl=1.33-1.79) of an asthma attack requiring GP consultation for an increase of 17.6 grains $/ \mathrm{m}^{3}$ of Poaceae counts, the small corresponding p-value providing good evidence of a relationship even after a Bonferroni correction.

\section{Discussion}

This time-series study carried out in a primary health care setting in the Greater Paris area enabled us to quantify the form and magnitude of the relationship between different types of pollens and asthma attacks requiring a GP consultation, after controlling for potential confounders including meteorological variables, air pollutants and influenza. The model analysing a single pollen at once (single pollen model) suggests a significant and positive linear relationship between Betula and Poaceae pollen counts and the number of asthma attacks, and a non-linear relationship for Cupressa pollens. Using the model including all pollens at the same time (multi-pollen model), only Poaceae pollen counts were highly significantly associated with an increase in asthma attacks. High correlations between Poaceae, Fraxinus and Betula, ranging from 0.5 to 0.8 , could explain changes in the magnitude and significance of associations observed in the multi-pollen model compared to the single pollen model.

Our results are consistent with previous investigations which have reported significant positive associations between asthma morbidity outcomes and different pollen types at the secondary care level. ${ }^{11,12,24-26}$ Tobias et al. have reported a significant positive association between Poaceae and asthmarelated ER admissions in Madrid. ${ }^{12}$ However, such findings identified a non-linear relationship on a daily basis, in contrast with our findings. Stieb et al. have shown a positive linear association between grass pollen and ER attendances in Saint John (Canada). ${ }^{11}$ This association was significant only in a single pollen model and measured the effect of the grass pollen family without analysing the individual pollen components such as Poaceae. Lewis et al. have also reported a significant association between grass pollen and emergency visits for asthma in Derby (England), using another statistical modelling approach. ${ }^{24}$

From the analytical point of view, an added value of our study compared to the previous ones is provided by the use of generalised additive models (GAM) taking into account potential confounders and modifiers. This flexible nonparametric statistical model is widely used in time-series analysis, in particular in the investigation of air pollutant effects, since it does not require knowledge of the nature of

Table 3. Adjusted relative risks (RR) and $95 \%$ confidence intervals (CI) for GP consultations for asthma attacks for an inter-quartile range (IQR) increase in pollen counts, Paris and surrounding area, 2003-7.

\begin{tabular}{lcccccccc} 
& \multicolumn{3}{c}{ Model with one pollen } & \multicolumn{3}{c}{ Model adjusted for all types of pollens } \\
\hline & IQR $\left(\right.$ grains $\left./ \mathrm{m}^{3}\right)$ & RR & IC & p value & RR & IC & p value \\
\hline Betula & 16.3 & 1.073 & $1.038-1.109$ & $<0.0001$ & 1.037 & $1.002-1.073$ & 0.0396 \\
Fraxinus & 7.1 & 1.054 & $1.008-1.102$ & 0.0195 & 0.987 & $0.944-1.032$ & 0.5738 \\
Poaceae & 17.6 & 1.700 & $1.469-1.968$ & $<0.0001$ & 1.540 & $1.331-1.790$ & $<0.0001$
\end{tabular}


the association contrary to generalised linear models. ${ }^{27,28}$ In the GAMs, the mean of a response variable is related to a sum of unspecified non-parametric smoothing functions applied to independent variables such as weather or pollen counts. The estimated non-parametric functions can then reveal nonlinearities in the effects of these variables. In our study, the relationship between Poaceae pollens and the number of asthma attack cases appeared to be linear. Moreover, asthma attacks as seen by GPs were investigated in our study, which has not been previously documented. This figure includes attacks of wheezing, asthma, and breathlessness requiring medical intervention, with the exclusion of ordinary asthma consultations for treatment, check-up, follow-up; but this is a tiny fraction of all asthma attacks seen in metropolitan France, ${ }^{13}$ where most severe asthma attacks are seen in the ER Departments of hospitals.

Our findings must be interpreted with caution due to some data limitations. From the methodological point of view, the sample of GPs providing the data on numbers of asthma exacerbations could have been biased. However, the representative nature of the FNS has been discussed at length ${ }^{15}$ and the GPs were not particularly notified about our survey on the links between pollens and asthma attacks, which could have influenced their responses. Asthma attacks were identified on the basis of a standardised definition already used in epidemiological studies for physician assessment during a medical visit, which diminishes the risk of mis-classification of the cases. From the statistical point of view, the low incidence of asthma attacks reported by GPs did not limit the statistical power of the relationships between pollens and asthma attacks even after allowing for confounders.

Another methodological limitation of our study comes from the fact that the investigation of short-term effects of pollen counts on asthma was not made on a daily basis, since GPs only reported on a weekly basis. This constitutes a constraint on our results since the exposure of airborne allergenic pollens may induce delayed adverse effects with a lag from 0 to 3 days. 12,24,26 Moreover, the effects of variables such as "Bank Holidays" or "Sundays" or "thunderstorms" could not be explored, although some studies have suggested that they were associated with asthma outbreaks. ${ }^{29}$ However, various lags were used, and the lag 0 , the one on the same week as the asthma attacks counts, provided the best fit of the models.

Mis-classification of exposure could also have occurred. Pollen counts obtained from a unique monitoring station were considered as a proxy of individual exposure of asthma cases. Patients were not necessarily exposed to airborne pollen within the GP's office area, in particular in the holiday period. However, the RNSA has settled a representative network of monitoring stations for pollens for the Paris area.

The low average weekly incidence rate of 25.4 cases per
100,000 inhabitants could have under-estimated the relationship. Indeed, it can be expected that with a better assessment of asthma exacerbations, including also asthma attacks seen at the hospital, the relationship would have been even more significant. On the other hand, the number of weeks during which no cases (null incidence) were reported may have been overestimated due to the FSN system, which puts by default equal to zero the number of cases when not explicitly mentioned otherwise (no possibility of missing data). However, the statistical relationships and the figures we observed were robust.

\section{Conclusion}

Our study investigated for the first time the short-term effects of airborne pollens on asthma attacks presenting in GPs' clinics. A significant and linear relationship has been identified between Poaceae airborne pollens and asthma attacks requiring a GP consultation, with a $54 \%$ increase in the risk of asthma attacks for an IQR increase of 17.6 grains $/ \mathrm{m}^{3}$ of Poaceae. This relationship needs to be confirmed on a daily basis and using a more consistent time-series. If the link between airborne pollen counts and GP visits for asthma attacks is confirmed, the public health impact would be considerable. Considering that fatal asthma events can also occur in well-controlled asthmatics, and given the large number of GP consultations for asthma attacks, the impact of appropriate preventive measures during the pollen season could considerably reduce the risk of asthma attacks. ${ }^{30}$

\section{Conflict of interest declaration}

No conflict of interest.

\section{Acknowledgements}

Bich Tram Huynh was a recipient of a fellowship of the Caisse Primaire d'Assurance Maladies, France.

\section{References}

1. Asher MI, Montefort S, Bjorksten B, et al. Worldwide time trends in the prevalence of symptoms of asthma, allergic rhinoconjunctivitis, and eczema in childhood: ISAAC Phases One and Three repeat multicountry cross-sectional surveys. Lancet 2006;368:733-43. http://dx.doi.org/10.1016/S0140-6736(06) 69283-0

2. D'Amato G. Environmental urban factors (air pollution and allergens) and the rising trends in allergic respiratory diseases. Allergy 2002;57 Suppl 72:30-3. http://dx.doi.org/10.1034/j.1398-9995.57.s72.5.x

3. D'Amato G, Cecchi L. Effects of climate change on environmental factors in respiratory allergic diseases. Clin Exp Allergy 2008;38:1264-74. http://dx.doi.org/10.1111/j.1365-2222.2008.03033.x

4. D'Amato G, Cecchi L, Bonini $S$, et al. Allergenic pollen and pollen allergy in Europe. Allergy 2007;62:976-90. http://dx.doi.org/10.1111/j.1398-9995.2007. 01393.x

5. Anderson HR, Ponce de Leon A, Bland JM, Bower JS, Emberlin J, Strachan DP. Air pollution, pollens, and daily admissions for asthma in London 1987-92. Thorax 1998;53:842-8. http://dx.doi.org/10.1136/thx.53.10.842

6. Galan I, Tobias A, Banegas JR, Aranguez E. Short-term effects of air pollution 
Pollens and asthma attacks seen by GPs

on daily asthma emergency room admissions. Eur Respir J 2003;22:802-08. http://dx.doi.org/10.1183/09031936.03.00013003

7. Hajat S, Haines A, Goubet SA, Atkinson RW, Anderson HR. Association of air pollution with daily GP consultations for asthma and other lower respiratory conditions in London. Thorax 1999;54:597-605. http://dx.doi.org/10.1136/ thx.54.7.597

8. Erbas B, Chang JH, Dharmage $S$, et al. Do levels of airborne grass pollen influence asthma hospital admissions? Clin Exp Allergy 2007;37:1641-7. http://dx.doi.org/10.1111/j.1365-2222.2007.02818.x

9. Hanigan IC, Johnston FH. Respiratory hospital admissions were associated with ambient airborne pollen in Darwin, Australia, 2004-2005. Clin Exp Allergy 2007;37:1556-65.

10. Rossi OV, Kinnula VL, Tienari J, Huhti E. Association of severe asthma attacks with weather, pollen, and air pollutants. Thorax 1993;48:244-8. http://dx.doi.org/10.1136/thx.48.3.244

11. Stieb DM, Beveridge RC, Brook JR, et al. Air pollution, aeroallergens and cardiorespiratory emergency department visits in Saint John, Canada. J Expo Anal Environ Epidemiol 2000;10:461-77. http://dx.doi.org/10.1038/ sj.jea.7500112

12. Tobias A, Galan I, Banegas JR. Non-linear short-term effects of airborne pollen levels with allergenic capacity on asthma emergency room admissions in Madrid, Spain. Clin Exp Allergy 2004;34:871-8. http://dx.doi.org/ 10.1111/j.1365-2222.2004.01983.x
13. Hanslik T, Toubiana L, Flahault A. Crises d'asthme de l'adulte: entre 1 et 1,5 million de consultations par an en médecine génerale. Info Respiration 2002; 49:19-20.

14. http://www.sentiweb.fr/.

15. Flahault A, Blanchon T, Dorleans Y, Toubiana L, Vibert JF, Valleron AJ. Virtual surveillance of communicable diseases: a 20-year experience in France. Stat Methods Med Res 2006;15:413-21.

16. Costagliola D, Flahault A, Galinec D, Garnerin P, Menares J, Valleron AJ. A routine tool for detection and assessment of epidemics of influenza-like syndromes in France. Am J Public Health 1991;81:97-9. http://dx.doi.org/ 10.2105/AJPH.81.1.97

17. http://www.pollens.fr.

18. www.ademe.fr.

19. www.meteofrance.com.

20. Institut de veille sanitaire. Séries temporelles et modèles de régression. Application à l'analyse des associations à court terme entre la pollution atmosphérique et la santé. http://www.invs.sante.fr/publications/2005/ series_temporelles/ Last date accessed: December 18, 2008.

21. Hastie TJ , Tibshirani RJ. Generalized additive models. New York, NY: Chapman and Hall, Inc. 1990.

22. Richardson S. [Methodological problems in health-environment ecological studies]. C R Acad Sci III.

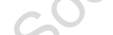

\section{Available online at http://www.thepcrj.org}

